Economia e Sociedade, Campinas, Unicamp. IE.

http://dx.doi.org/10.1590/1982-3533.2021v30n3art11

\title{
Faces e lados ocultos na estrutura tributária capitalista *
}

\author{
Luís Carlos Dalmolin **
}

\section{Resumo}

Este artigo, resultado de pesquisas destinadas à dissertação de mestrado acadêmico, apresenta dados de algumas das principais pesquisas acerca da desigualdade, concentração (de renda e capital) e das estruturas tributárias no mundo, na América Latina e, de forma mais detalhada, no Brasil. Verifica e apresenta indícios de que, no país, os trabalhadores assalariados são proporcionalmente mais tributados do que os megaempresários, contraditando teorias adeptas da neutralidade Estatal. Adicionalmente, constata alguns efeitos negativos da estrutura tributária e concentração de renda em desfavor dos pequenos e médios empresários (PME). Ao final, elenca diferentes mecanismos tributários intrínsecos ao STB à disposição efetiva, principalmente, dos megaempresários e das grandes corporações, apontando a possibilidade real da transferência do ônus tributário em desfavor dos trabalhadores assalariados e da minoração dos lucros dos PME, fato que leva a questionamentos sobre os limites da tributação, enquanto remédio prescrito à correção de injustiças sociais, no âmago do sistema capitalista.

Palavras-chave: Sistema Tributário Brasileiro, Economia, Iniquidades socioeconômicas.

\begin{abstract}
Hidden sides of the capitalist tax structure

This article, the result of a master's thesis research, presents data from some of the main research on inequality, concentration (of income and capital) and tax structures in the world, in Latin America and, in more detail, in Brazil. It verifies and presents evidence that in Brazil salaried workers are proportionally more heavily taxed than mega-entrepreneurs, contradicting theories that adhere to State neutrality. Additionally, it presents some of the negative effects of the tax structure and income concentration to the detriment of small and medium-sized entrepreneurs (SMEs). Finally, it lists different tax mechanisms intrinsic to the Brazilian tax system (STB) at the effective disposal, mainly of mega-entrepreneurs and large corporations, highlighting the real possibility of transferring the tax burden to the disadvantage of salaried workers and the reduction of profits of SMEs. This leads to questions on the limits of taxation, as a remedy prescribed for the correction of social injustices, at the heart of the capitalist system.
\end{abstract}

Keywords: Brazilian Tax System, Economy, Socioeconomic Inequities. JEL: H20, H23, B14.

Tendo em vista alguns estudos sobre a desigualdade e concentração de renda no mundo especialmente no Brasil ${ }^{1}$-, os quais têm dado enfoque particular à tributação como meio eficiente na diminuição dessas características, esta pesquisa se debruça sobre o Sistema Tributário Brasileiro (STB), buscando evidenciar sua formatação estrutural. Anseia descobrir se, de fato, a estrutura tributária brasileira tende à neutralidade, à indiscriminação de grupos e classes sociais ou se existem discrepâncias estruturais que dão gênese às iniquidades tributárias perpetuando as desigualdades socioeconômicas, hipótese central da presente pesquisa. Para poder investigar tal hipótese, é utilizada

\footnotetext{
${ }^{*}$ Artigo recebido em 14 de janeiro de 2020 e aprovado em 29 de abril de 2021.

${ }^{* *}$ Mestre em Políticas Sociais pela Universidade Federal do Rio Grande do Sul (UFRGS), Porto Alegre, RS, Brasil. E-mail: lcdalmolin@outlook.com. ORCID: https://orcid.org/0000-0001-7251-8069.

(1) Uma criança que nasce pobre, hoje, no país, poderá levar nove gerações para alcançar a renda média. Disponível em: http://www.oecd.org/brazil/social-mobililty-2018-BRA-PT.pdf. Acesso em: 17 jun. 2018.
} 
estritamente a legislação tributária vigente aplicada e, quando necessário, simulações contábeisnuméricas, relacionando os resultados com amplas fontes bibliográficas, predominantemente críticas ao STB. Na ordem, este artigo apresenta a concentração e desigualdade de renda e capital no mundo, na América Latina e no Brasil, seguida da demonstração de como os estudos críticos ao STB vêm tecendo proposições de reformas tributárias. Posteriormente, pleiteia evidenciar parte da essência da estrutura tributária brasileira e os mecanismos funcionais que proporcionam aos megaempresários menor ônus tributário. Por fim, esboça as considerações finais.

Por meio de abordagens majoritariamente quantitativas extraídas de fontes bibliográficas e documentais, o estudo buscará encontrar e analisar os dados contábeis, estatísticos e matemáticos referentes à tributação indireta e direta destinadas às Pessoas Físicas (PF) e Pessoas Jurídicas (PJ) situadas no Brasil. Tais dados, por exemplo, inerentes ao faturamento bruto e à lucratividade das empresas, à renda e capital das $\mathrm{PF}$ e PJ, serão extraídos (dentre outras fontes) dos relatórios publicados pelo Ministério da Fazenda, Sebrae, Comitê Gestor do Simples Nacional, empresas de auditoria, publicações contábeis obrigatórias (Lei das S/A - 6.404/76), Comissão de Valores Mobiliários (CVM), Instituto Brasileiro de Geografia e Estatística (IBGE), Banco Central do Brasil (Bacen) e estudos divulgados pela RFB. Após, esses dados serão sistematizados e analisados de forma comparativa à luz da revisão da literatura.

\section{Concentração de renda e capital versus estrutura tributária no mundo}

A concentração e a desigualdade de renda e capital no mundo vêm aumentando em todos os continentes, principalmente após a década de 1970. Na Europa, a concentração aproxima-se da do período anterior às guerras, em que a relação capital/renda $(\beta)$ era de aproximadamente $700 \%$, ou seja, o capital representava 7 anos do total da renda nacional. Do mesmo lado, a taxa de remuneração do capital (r) está se descolando de forma positiva da taxa do crescimento (g), promovendo a força de divergência, em que $r>g$. Empiricamente, o décimo superior da renda possuía cerca de $35 \%$ de toda a renda nacional na Europa em 2010. Nos EUA, a situação é ainda pior, pois 45-50\% do total da renda nacional é apropriada pelo decil superior, sendo que o centésimo do topo observou sua renda aumentar aproximadamente $300 \%$ nos últimos 30 anos, enquanto a renda dos $50 \%$ menos favorecidos se manteve praticamente estática (Piketty, 2014; Oxfam, 2017a). Em correlação com a concentração e a desigualdade de renda e capital, a tributação ${ }^{2}$ sobre essas bases vem decrescendo sensivelmente, conforme comprovou o francês Thomas Piketty (2014). Contudo, no ano de 2017, esse autor reviu suas indicações, esboçadas em sua principal obra, as reavaliou e apontou que pode ter dado muita significância à tributação progressiva do capital para diminuir a desigualdade. Sugere, concomitantemente, outras políticas sociais (Piketty, 2017).

Alguns relatórios (FMI, 2017; Cepal, 2015) apuraram os efeitos redistributivos das políticas fiscais, agrupando e, em seguida, segregando os efeitos da tributação direta e os gastos com saúde e educação. Na América Latina (AL), o resultado da política fiscal diminuiu em 17,65\% a desigualdade de renda medida pelo índice de Gini. No Brasil, esse efeito representou quase o dobro do da AL,

(2) Os EUA tributavam as rendas com taxas de até $70 \%$ em 1980, passando a $28 \%$ em 1988. As heranças eram tributadas entre $70-80 \%$, passando a apenas 35\% em 2010. No Reino Unido, a taxação sobre a renda era de $90 \%$ em meados de 1980, diminuindo para 40\% por volta de 1990 . 
diminuindo em 33,25\% a desigualdade medida pelo mesmo índice. Em sintonia e maior especificidade, o estudo da Cepal (2015) revelou que dois terços da redução do coeficiente de Gini advêm das transferências públicas - gastos com saúde e educação -, e não da tributação. Isso não quer dizer que a tributação não é um instrumento importante na redistribuição de renda, mas, sim, que ela está sendo subutilizada, principalmente pela massiva tributação sobre o consumo (regressiva).

Estudos inerentes à $\mathrm{AL}$ a indicam como uma das regiões com maior desigualdade de renda no mundo ${ }^{3}$, embora tenham verificado uma tendência de queda nos índices de desigualdade, diferente da maioria dos países. Dentre as principais barreiras apontadas pelas pesquisas para diminuir a desigualdade estão: a carga tributária ${ }^{4}$ estreita, o descenso das alíquotas marginais da taxação da renda, o alto índice de evasão e de benefícios tributários e a falta de equidade vertical e horizontal. Esses fatores contribuem expressivamente para o não desenvolvimento da região, bem como para o aumento das desigualdades de renda e capital (Jiménez, 2017; Paes 2017; Hanni; Martner, 2017). Apesar de Paes (2017) ter verificado que a tributação do Imposto de Renda de Pessoa Física (IRPF) teve incremento ${ }^{5}$ de $33 \%$ na AL em relação ao Produto Interno Bruto (PIB), esse tributo, na região, contribuiu modestamente para diminuir $2 \%$ da desigualdade no ano de 2014. Na União Europeia (UE) este percentual foi de 12,5\% em um grupo de 18 países $^{6}$ (Hanni; Martner, 2017). O mesmo (a diminuição da desigualdade socioeconômica) não ocorre quando se compara a arrecadação do Imposto de Renda de Pessoa Jurídicas (IRPJ) com o PIB per capita, ratificando o enunciado de Jiménez (2017) ao imputar às pessoas jurídicas alíquotas marginais inferiores e temporalmente decrescentes ${ }^{7}$ em comparação com a média da OCDE.

Outro ponto a ser destacado, e que é trazido à luz nos estudos da OCDE et al. (2018), diz respeito à forte tributação sobre o consumo (mais de 50\%) na $\mathrm{AL}$, principalmente por meio do Imposto sobre Valor Agregado (IVA), cuja finalidade principal é meramente a simplificação/racionalização dos sistemas tributários (recomendada ${ }^{8}$ ao Brasil pela OCDE (2018)), ratificando o caráter de classe desta instituição ao indicar a manutenção da estrutura tributária voltada ao consumo.

\section{Concentração de renda e capital no Brasil}

Para se ter uma ideia do tamanho das desigualdades socioeconômicas brasileiras e dos limites de renda para se enquadrar em um determinado decil, será inserida a seguinte tabela, elaborada por um aluno orientando do próprio Piketty:

\footnotetext{
(WTID).

(3) A média da renda do $1 \%$ mais rico da AL chegou a comportar 27,9\% em 2016, segundo a World Top Incomes Database

(4) A média da carga tributária da AL em relação ao PIB é de 22,7\%, enquanto a média dos países-membros da OCDE é de 34,3\% (OCDE, 2017), extraídos em 03 de abril de 2018, às 15 h28.

(5) No Brasil, de 1990 a 2010, a participação do IRPF em relação ao total de receitas diminuiu em torno de 5\%.

(6) Entretanto, é no confronto dos dados do PIB per capita com o IRPF que se evidencia a relação positiva de um frente ao outro (OCDE et al., 2018).

(7) Tendência que vem sendo seguida pela maioria de países, a exemplo da recente alteração tributária dos EUA.

(8) Segundo Fagnani et al. (2018) e Salvador (2014), a extinção do PIS e da Cofins representaria, na prática, o fim do financiamento da seguridade social acolhida pela Constituição Federal de 1988.
} 
Tabela 1

Limites de renda e participações nos rendimentos no Brasil, 2015

\begin{tabular}{lcccc}
\hline Grupo de Renda & No. de Adultos & Limite de Renda & Renda Média & Participação de \\
\hline População Total & 142.540 .336 & $\mathrm{R} \$ 0,00$ & 26,242 & $100 \%$ \\
Inferior 50\% & 71.270 .168 & $\mathrm{R} \$ 0,00$ & 6,549 & $12,5 \%$ \\
Interm. 40\% & 57.016 .134 & $\mathrm{R} \$ 12,961$ & 22,376 & $34,1 \%$ \\
Topo 10\% & 14.254 .034 & $\mathrm{R} \$ 43,803$ & 140,174 & $53,4 \%$ \\
Topo 1\% & 1.425 .403 & $\mathrm{R} \$ 216,849$ & 622,239 & $23,7 \%$ \\
Topo 0,1\% & 142.540 & $\mathrm{R} \$ 797,290$ & $2.881,959$ & $11 \%$ \\
Topo 0,01\% & 14.254 & $\mathrm{R} \$ 3.525,915$ & $14.184,637$ & $5,4 \%$ \\
Topo 0,001\% & 1.425 & $\mathrm{R} \$ 31.189,964$ & $65.015,386$ & $2,5 \%$ \\
\hline
\end{tabular}

Fonte: Morgan (2017, p. 239).

As excrescências que podem ser percebidas pela Tabela 1, demonstram, por exemplo, que enquanto os $50 \%$ mais "pobres" ficam com $12,5 \%$ da renda nacional, o $0,1 \%$ mais "rico" fica com $11 \%$. No entanto, este $1 \%$ é tão heterogêneo que para fazer parte das 1.425 pessoas mais privilegiadas é necessária uma renda mínima mensal de 31 milhões de reais. Os dados acima apresentados são similares aos dados encontrados por Medeiros, Souza e Castro (2015) e Gobetti e Orair (2015; 2017), os quais revelaram que os dados das pesquisas domiciliares brasileiras (PNAD, POF e Censo) não evidenciam a realidade, mas, ao contrário, a subestimam.

Sobre a hegemonia e a estabilidade do $1 \%$ mais rico no país, os seguintes estudos verificaram: no Brasil, desde a década de 1970, o 1\% mais rico deteve, em média, 25\% da renda nacional (Morgan, 2015). Corroborando e estendo consideravelmente a série histórica, que foi do ano de 1926 a 1913 , Souza e Medeiros (2015) relatam que nesse período o $1 \%$ mais rico oscilou sua concentração de renda em torno de $20 \%$ a $25 \%$ da renda nacional. Esses autores apontam tal excrescência em todo século XX, com maior concentração desse $1 \%$ durante o período do golpe militar de 1964. Esse achado foi ratificado pelo relatório da Oxfam (2017b), segundo o qual, no Brasil, apenas seis pessoas possuem o mesmo patrimônio de 100 milhões de brasileiros. Em contraste, há 16 milhões de pessoas que vivem abaixo da linha da pobreza (Gobetti; Orair, 2015; 2017).

\section{Tributação no Brasil e as proposições de reformas}

Acerca da estrutura tributária, Gobetti e Orair $(2015 ; 2017)$ verificaram, assim como verificou Salvador (2016) e Fagnani et al. (2018), principalmente o seguinte: inexistência de equidade vertical e horizontal'; efeitos nocivos dos benefícios fiscais (principalmente isenção de lucros e/ou dividendos); tributação progressiva em queda nos anos de 2007-2013; e progressividade advinda quase totalmente das alíquotas sobre os rendimentos oriundos do trabalho quando comparadas com as alíquotas imputadas às rendas do capital, sendo essas últimas muitas vezes isentas de tributação e, quando tributadas na fonte, recebendo alíquotas neutras.

(9) Sumariamente equidade vertical ocorre quando quanto maior a renda maior a tributação, já a equidade horizontal se dá quando diferentes tipos originários de rendimento são tributados de forma semelhante. 
Foi na década de 1990 que ocorreram as maiores alterações na legislação do Imposto de Renda sobre o lucro das empresas, mas que não foram revogadas pelos seus sucessores. Concomitantemente, nesse ínterim, as empresas foram agraciadas com redução de alíquota nominal, que passou de $25 \%$ para apenas $15 \%$. Com relação ao adicional ${ }^{10}$, as alíquotas decresceram de $18 \%$ ou $12 \%$ fixando-se em $10 \%$. Apesar de indicarem a tendência global à desoneração das empresas, as análises das alíquotas nominais são frágeis se feitas de forma isolada, pois, no caso brasileiro, além da redução da alíquota, os benefícios (como a isenção de lucros e dividendos e a inserção dos Juros Sobre o Capital Próprio) concedidos às empresas sobre as bases de cálculo foram determinantes. Como resultado dessas políticas, Gobetti e Orair $(2015 ; 2017)$ perceberam que os rendimentos (oriundos de lucros e dividendos isentos de IRPF) dos empresários passaram de 149 bilhões, em 2007, para 287 bilhões, em 2013, um crescimento superior a $41 \%$ do crescimento do PIB do mesmo intervalo, representando 2,1 milhões de declarantes, sendo boa parte deles identificada no topo da renda fiscal.

Lettieri (2017), Morgan (2017), Introíni e Moretto (2017), Salvador (2014; 2016) e Gobetti e Orair $(2015 ; 2017)$ apontaram tributação bem mais incisiva sobre os rendimentos dos trabalhadores se comparada com a tributação que recai sobre o capital. De acordo com Gobetti e Orair $(2015 ; 2017)$, essas nuances tendem a realçar a polarização da renda oriunda do trabalho frente à renda dos mais ricos. Os autores descobriram que, no topo da renda brasileira, estão $71.440^{11}$ pessoas que auferiram rendimentos superiores a 1,3 milhão no ano-calendário de 2013. Dessas, 51.419 são recebedoras de rendas empresariais, ou seja, o topo da renda é predominantemente habitado por indivíduos que possuem rendas advindas de empresas - os megaempresários.

A maioria das pesquisas investigadas pelo presente estudo fizeram proposições para que o STB deixe de acentuar a concentração e a desigualdade de renda e para que seja alocado ao lado do que Piketty (2014) recomendou. Em comum, elas: propuseram o fim da isenção do imposto sobre a renda, advinda dos lucros e dividendos; orientaram haver maior tributação sobre o patrimônio e menor sobre o consumo e recomendaram o fim da possibilidade de remunerar os empresários por meio dos juros sobre o capital próprio.

O desafio momentâneo deste estudo é investigar a estrutura tributária brasileira observando as causas gerais de efeitos deletérios à maioria da sociedade, lançando à analise os meios (e quem detém condições de utilizá-los) tributários legais e paralelos que aprofundam problemas econômicos e sociais.

Para isso, resumidamente, far-se-á um esboço da atual formatação tributária brasileira. Destaca-se que os principais tributos indiretos (cujo ônus tributário recaí sobre o consumo de pessoas físicas e jurídicas) são o $\operatorname{ICMS}^{12}$, de competência dos estados, o ISSQN ${ }^{13}$, de competência dos

(10) Atualmente o adicional (de 10\%) é um percentual que se aplica quando a base tributável é maior do que 20 mil reais.

(11) Representando $0,05 \%$ da população brasileira.

(12) Imposto sobre Operações relativas à Circulação de Mercadorias e sobre Prestações de Serviços de Transporte Interestadual e Intermunicipal e de Comunicação.

(13) Imposto sobre Serviços de Qualquer Natureza. 
municípios, o PIS ${ }^{14}$, a Cofins ${ }^{15}$ e o IPI ${ }^{16}$, de competência da União. Por outro lado, os principais tributos de natureza direta (os quais recaem sobre a renda e o capital de pessoas físicas e jurídicas), são o Imposto de Renda e a CSLL ${ }^{17}$, de competência da União, o $\operatorname{ITCD}^{18}$ e o IPVA ${ }^{19}$, de competência dos estados, e o ITBI $^{20}$ e IPTU ${ }^{21}$, de competência dos municípios.

A palavra competência refere-se à Competência Tributária, que "é a habilidade privativa e constitucionalmente atribuída ao ente político para que este, com base na lei, proceda à instituição da exação tributária" (Sabbag, 2020, p. 339).

\section{O mecanismo da translação do ônus tributário}

Incialmente, parte-se da seguinte indagação: até que ponto a tributação legalmente destinada aos megaempresários e às megaempresas, (não) pode ser repassada aos consumidore $^{22}$ via tributos indiretos, aos trabalhadores assalariados por meio da minoração dos salários diretos e indiretos ou, complementarmente, aos PME por meio da compressão dos seus lucros?

Antes que, sem aferições profundas, essa indagação possa ser descartada sob o pretexto de que os grandes empresários não teriam como transferir tal custo - da tributação dos lucros e dividendos pelo IRPF e/ou IRPJ e CSLL - ou compensar o aumento da taxação majorando o lucro, devido à concorrência imanente ao mercado ou à não aceitabilidade dos consumidores e trabalhadores assalariados em arcar com tais custos, é interessante observar a pesquisa de James O'Connor (1977) sobre o monopólio empresarial dos Estados Unidos e sua respectiva "tranquilidade" em imputar aos consumidores e aos trabalhadores os seus custos tributários mantendo seus lucros intactos ou crescentes. Especificamente sobre o caso brasileiro, o estudo da Receita Federal do Brasil inerente à incidência da carga tributária sobre os salários, desenvolvido por Rodrigues et al. $(1998$, p. 7$)$ é didático e aponta:

A ideia subjacente à translação é que, consideradas as condições do mercado, o empresário poderia em maior ou menor grau, esquivar-se do pagamento do tributo mediante redução dos salários pagos aos seus empregados, mantendo constante o custo da mão-de-obra.

Embora os autores ${ }^{23}$ estivessem versando sobre as contribuições patronais, não há impeditivo que torne esse mecanismo menos eficiente para transferência de qualquer outro tributo. Tanto é assim que Siqueira et al. (2017, p. 502) descrevem o referido mecanismo da seguinte forma: "O IRPJ pode ser repassado para frente para os consumidores (via aumento dos preços), repassado para trás para o

(14) Programa de Integração Social.

(15) Contribuição para o Financiamento da Seguridade Social.

(16) Imposto sobre Produtos Industrializados.

(17) Contribuição Social sobre o Lucro Líquido.

(18) Imposto sobre a Transmissão “Causa Mortis” e Doação de Quaisquer Bens e Direitos.

(19) Imposto sobre a Propriedade de Veículos Automotores.

(20) Imposto sobre Transferência de Bens Imóveis.

(21) Imposto sobre a Propriedade Territorial Urbana.

(22) Mészáros (2015) trata o termo "consumidor" como uma forma fetichista imbricada a ofuscar a compra dos produtos por aqueles que o produziriam; os trabalhadores assalariados. À semelhança de Pierre Bourdieu (2001).

(23) Semelhantemente, Musgrave e Musgrave (1980) atribuem as transferências de tributos patronais aos trabalhadores, assim como o fez D'Araújo (2015). 
trabalho (via redução de salários) [...]". O mesmo raciocínio é observado pela Tax Foudation. Aliás, sobre a translação do próprio imposto de renda, O’Connor (1977, p. 207), citando Krzyzaniak (1966), transcreveu:

Conforme os pressupostos econômicos especiais, pode ser defendido que as empresas transferem o imposto de renda não só para os consumidores como, também, para os próprios trabalhadores, na forma de salários mais baixos e, também, aos investimentos do setor não tributado.

Em relação ao Brasil, é necessário observar estudos elaborados pelo Centro de Estudos Tributários e Aduaneiros do Ministério da Fazenda - Brasil (2015; 2018). Os dados presentes nesses relatórios ${ }^{24}$ (que apontam a elevadíssima concentração de capital por poucas empresas monopolistas e oligopolistas) levam a crer que as "forças do mercado", ao invés de contrariarem os interesses privados oligopolistas, serão e estão voltadas contrariamente tanto aos micros, pequenos e médios empresários, os quais fazem parte do setor competitivo ${ }^{25}$ descrito por O'Connor (1977), quanto aos consumidores, em especial aos trabalhadores assalariados, os quais são altamente taxados na renda oriunda do trabalho assalariado e, concomitantemente, pelo consumo.

Intimamente relacionado com a concentração de receitas nas pessoas físicas dos megaempresários, o estudo (Brasil, 2020) evidenciou a desproporcional concentração da receita bruta total em favor das empresas enquadradas no Lucro Real em relação às demais ${ }^{26}$. Em 2018, enquanto as empresas enquadradas nos regimes tributários do Lucro Presumido e Simples Nacional juntas representam $82,72 \%$ do total de empresas no Brasil, percebendo apenas $15,36 \%$ de toda a receita bruta, as empresas enquadradas no Lucro Real, que conformam meramente $1,38 \%{ }^{27}$ do total de empresas no país, auferiram $81,55 \%$ do total da receita bruta no mesmo ano, comprovando a onipresente e hegemônica (em termos de rendimentos das atividades) presença dos conglomerados empresariais no país. Talvez seja importante destacar, que do total de "empresas" brasileiras, 41,21\% são compostas por Microempreendedores Individuais (MEI), ou seja, formadas por um único "empreendedor", o qual passou a ser detentor de um CNPJ.

Em contraste com a altíssima concentração de receitas apropriadas pelas empresas optantes pelo Lucro Real, o que poderia levar a suposições de que as mesmas empregam muito mais trabalhadores do que as demais, verifica-se que aquelas empregaram, em 2018, cerca de 37,88\% do total de trabalhadores celetistas, enquanto as empresas enquadradas no Lucro Presumido e Simples Nacional, detinham $41,78 \%$ dos empregos formais. Outro ponto a ser observado é o aumento da concentração de renda entre as empresas, quando comparados o relatório do ano de 2015 , frente ao relatório emitido em 2020, pelo Ministério da Fazenda.

(24) O relatório anterior, emitido por Brasil (2015), demonstrou que as 10 maiores empresas de cada segmento se apropriam de, por exemplo: Extração de minerais metálicos - Receita Bruta (Top10): Extração de carvão mineral - Receita Bruta (Top10): 94 \%; Extração de minerais metálicos - Receita Bruta (Top10): 85\%; Fabricação de bebidas - Receita Bruta (Top10): 63\%; Fabricação de produtos do fumo - Receita Bruta (Top 10): 95\%; Fabricação de produtos derivados do petróleo e de biocombustíveis - Receita Bruta (Top 10): 93\%; Extração de petróleo - Receita Bruta (Top 10): 76\%.

(25) Ver o conceito de setor competitivo, monopolista e estatal na obra de James O’Connor (1977). específica.

(26) Lucro Real, Presumido e Simples Nacional são tipos de enquadramentos tributários, com tributação diversa e legislação

(27) Percentual que se mostra tendente a maior concentração desde 2009. 
Pode ser que existam ou surjam estudos que, ao contrário desse, concebam a ideia de que as empresas enquadradas no Lucro Presumido e no Simples Nacional são bem mais numerosas, indiciando que essas empresas acham esses regimes mais benéficos e, por isso, optam por eles. Apesar deste estudo não tender ao planejamento tributário, tal hipótese, afora de em partes poder ser verdadeira, ofusca a finalidade central, ou seja, na mesma perspectiva descrita por Cattani (2018), se começaria a estudar a pobreza, e não a riqueza, uma vez que a concentração de receitas está hegemonicamente nas empresas enquadradas no Lucro Real. Não está a se defender os regimes Simples Nacional e Lucro Presumido, pois eles não permitem a tributação efetiva sobre o excedente de renda e facilitam planejamentos tributários. Contudo, ao se inclinar a encontrar os principais problemas nesses regimes, permite-se a perpetuidade do status quo das grandes empresas e empresários, que majoritariamente estão enquadrados no Lucro Real.

Uma pesquisa inerente à estrutura tributária brasileira, verificou, por meio de análises orçamentárias, que os tributos patronais sobre a folha de pagamento (INSS, FGTS, RAT e Sistema S), sobre a receita bruta (IPI, ICMS, PIS, Cofins) e sobre o lucro (IRPJ e CSLL) podem e tendem a ser transferidos (principalmente pelas grandes corporações) total ou em frações, aos preços dos produtos - aos consumidores -, aos funcionários como minoração de seus salários e/ou utilizando os dois artifícios. Além disso, relatou, que frente a cenários de alta monopolização como o atual, os PME, diferentemente dos megaempresários, são forçados a baixarem suas margens de lucros para permanecerem competitivos, uma vez que não podem repassar a carga tributária completa aos seus empregados e consumidores (Dalmolin, 2018).

Mesmo as reformas tributárias progressivas, que vêm sendo altamente recomendadas (como remédio às concentrações de renda e capital) por determinados campos ideológicos tidos como progressistas, possuem fragilidades oriundas da subordinação às leis capitalistas pouco aceitas pelos seus ideólogos. Exemplifica-se: suponha-se que por meio de uma reforma tributária houvesse uma diminuição da alíquota efetiva do imposto sobre o consumo de $50 \%$ para $30 \%$ e o aumento do Imposto de Renda da Pessoa Física (IRPF) do capitalista de $10 \%$ para $35 \%$. Considerando R $\$ 100,00$ o preço de uma mercadoria, a redução de $50 \%$ para $30 \%$ do imposto sobre o consumo faria aumentar em R\$ 20,00 o lucro da empresa, pois esse imposto diminuiria de $\mathrm{R} \$ 50,00$ para $\mathrm{R} \$ 30,00 .{ }^{28}$ Em relação ao Imposto de Renda da Pessoa Física (IRPF) do capitalista ocorreria o seguinte: antes da reforma, sua renda proveniente da venda dessa mercadoria era de $\mathrm{R} \$ 45,00$, já descontado o imposto $10 \%$ sobre a renda de $\mathrm{R} \$ 50,00(\mathrm{R} \$ 50,00-10 \%=\mathrm{R} \$ 45,00)$. Depois da reforma, a alíquota aumentada de 35\% incidirá sobre a renda também majorada (devido, como vimos, à diminuição do imposto sobre o consumo) de $\mathrm{R} \$ 70,00,(\mathrm{R} \$ 70,00-35 \%=\mathrm{R} \$ 45,50)$, resultando numa renda líquida semelhante para o capitalista, tanto antes quanto depois da reforma tributária.

Em suma, a redução do imposto sobre o consumo, mesmo que associado ao aumento do imposto sobre a renda do capitalista, não significa uma maior justiça tributária, pois, por um lado, nada obriga o capitalista a repassar a diminuição do imposto e reduzir os preços das mercadorias, o que poderia vir a beneficiar os trabalhadores e, por outro lado, o aumento da alíquota do imposto de

(28) Estamos considerando que o preço da mercadoria não se alteraria devido à redução do imposto sobre o consumo, uma vez que não há evidência histórica de que os preços dos produtos diminuirão por conta de reestruturações tributárias. 
renda do capitalista, ao incidir sobre um lucro mais elevado, poderá resultar em um lucro líquido deste, semelhante àquele anterior à reforma.

Destarte, a única força que poderia diminuir o efeito da translação, segundo Dalmolin (2018), seria a oriunda da concorrência no "mercado", a qual é praticamente inexistente no "andar de cima", referenciando o relatório do Brasil (2018) recentemente descrito. Claro que tal mecanismo não ocorre deliberadamente e que, justamente por isso, percebe-se que, quando a economia do país não está estável, os megaempresários forçam para minoração da carga tributária, uma vez que seu repasse total ou parcial não seria suportado pelos trabalhadores-consumidores e a minoração da margem de lucros dos PME poderia os levar à falência em massa. Assim, eles mesmos, os PME, se unem aos megaempresários na busca por menor tributação.

Nos setores em que haja forte concorrência, há a hipótese de que o empresário cederia às forças do mercado e não repassaria parte do ônus tributário, tirando de seu próprio lucro. Essa opção é plausível, mas, quando a verificação se dá nos pequenos e médios empresários do setor competitivo, pois quando observadas as empresas do setor monopolista, não há uma única evidência que auxilie na comprovação de que as forças do mercado obriguem os empresários e empresas do topo da distribuição de renda a procederem de tal forma, ainda mais com tamanha centralização dos meios de produção e concentração do capital.

No atual cenário econômico brasileiro, como foi destacado anteriormente, a presença de oligopólios que comandam hegemonicamente os principais segmentos da economia, desconstruindo qualquer teoria tendente à competitividade/concorrência e permitindo a translação de até $100 \%$ dos tributos como destacaram Rodrigues et al. (1998). Aliás, as "condições especiais do mercado" descritas pelos autores (p. 7), as "forças do mercado" ou os "pressupostos econômicos especiais" detalhados por O’Connor (1977, p. 207), ao invés de contrariarem os interesses privados oligopolistas/monopolistas, operam contra os micros, pequenos e médios empresários e, em especial, contra os trabalhadores assalariados (a massa que pouco faz com sua renda além de consumi-la em meios de subsistência).

\section{Mecanismos tributários em favor da elite empresarial}

Se, como foi visto, a concentração de renda das empresas se dá, hegemonicamente, nas que optaram pelo regime tributário do Lucro Real, que são as maiores em termos de renda no país, então elas merecem algumas outras verificações. Pois, além do mecanismo de transferência do ônus tributário, a elite empresarial, em especial os empresários oligopolistas, contam com amplos recursos legais para lançarem o ônus tributário às custas dos trabalhadores assalariados.

Conforme o art. 6o do Decreto-Lei 1.598/77, o conceito de Lucro Real é: "Lucro real é o lucro líquido do exercício ajustado pelas adições, exclusões ou compensações prescritas ou autorizadas pela legislação tributária". Traz-se à luz esse conceito porque o leitor poderia ser levado a imaginar que bastaria as empresas enquadradas no Lucro Real diminuírem as despesas e/ou custos das receitas para obtenção do Lucro Real, e que isso, então, serviria de base de cálculo para tributação. Ocorre que sobre o lucro contábil são necessários "ajustes", e é justamente nesses ajustes, os quais estão à disposição das empresas tributadas pelo Lucro Real, que residem diversos mecanismos para elidir ou mesmo evadir tributariamente. 
Nos anexos II e III da Instrução Normativa da Receita Federal do Brasil 1.700/17, combinados com os art. 249 e 250 do Regulamento do Imposto de Renda, estão todas as situações de adições ou exclusões da base de cálculo do IRPJ e da CSLL. Mas, para não tornar esta pesquisa demasiadamente extensa e tendente ao tecnicismo, serão trazidos alguns poucos exemplos de como podem ser utilizadas essas adições, exclusões ou compensações em favor das empresas. Um exemplo muito visto nas cisões, fusões e incorporações das grandes empresas por potentes grupos econômicos é a utilização do prejuízo fiscal da adquirida em favor da adquirente. No Brasil, por meio do art. 514 do Regulamento do Imposto de Renda, é vedado às empresas sucessoras utilizarem os prejuízos fiscais das sucedidas. Nasce, então, a figura oriunda do planejamento tributário, denominada usualmente incorporação às avessas, que nada mais é do que um artifício do qual as empresas se utilizam, em que a empresa controlada passa a incorporar a controladora, driblando a legislação e podendo assim compensar os prejuízos fiscais da empresa adquirida. Em suma, se uma empresa foi adquirida por 1 bilhão de reais, possuindo prejuízos fiscais a compensar de 700 milhões de reais, por exemplo, esse valor poderá ser compensado integralmente observado o limite por exercício de compensação.

Sobre os diversos mecanismos das adições e exclusões da base de cálculo das empresas tributadas pelo Lucro Real, será dado aqui, sinteticamente, o exemplo do Banco Santander na compra do Banco do Estado de São Paulo (Banespa). O Banco Santander registrou um ágio de 7,5 bilhões de reais pela compra do Banestado, cujo patrimônio líquido ficava em torno de 2,11 bilhões. Ocorre que são passíveis de exclusão (válida atualmente) da base de cálculo do IRPJ e da CSLL as parcelas mensais referentes à amortização desse ágio. Por meio desse mecanismo, segundo a descrição dos procuradores da Fazenda Nacional, o Banco Santander teria obtido vantagens tributárias no valor aproximado de 4 bilhões, quase o dobro do valor estimado do patrimônio líquido do Banespa.

A listagem de possibilidades de planejamentos para elidir tributariamente é extensa e, por certo, não caberia em uma única pesquisa, no entanto, tais abordagens procuram trazer indagações e pôr em xeque qualquer ato reformista que não as preveja.

\section{Evasão, remissão, paraísos fiscais e benefícios tributários: de que lado eles estão?}

Outros mecanismos potentes e complementares aos que estão sendo realçados residem na desigualdade - entre trabalhadores assalariados, PME e grandes empresas - da possibilidade de obtenção de benefícios tributários, remissão ou mesmo evasão de tributos. Se, entre a classe trabalhadora, a evasão tributária chega próximo de ser nula ${ }^{29}$ devido ao instituto legalizado da retenção na fonte que a impede de evadir; se, as PME não contam, na grande maioria, com corpo técnico capacitado para o devido planejamento (inclusive evasivo) e judicialização dos tributos; para os megaempresários esse mesmo instituto, da evasão tributária, proporciona condições de beneficiála como, por exemplo, por meio da apropriação indébita dos tributos retidos, de forma que a financie por (in)determinado período. Apesar de ser crime devidamente tipificado, depende de apuração do fisco e, não raras vezes, o saldo não é recebido pelas vias administrativas.

(29) Ver Rodrigues et al. (1998). 
Somado a isso, um estudo recentemente divulgado levantou os dados de contingências e provisões tributárias administrativas e judiciais de 114 empresas de capital aberto entre os anos 2008 e 2015. O estudo descobriu que a evasão tributária - originalmente tida pelas empresas como elisão - é vantajosa para as empresas, embora elas venham a ser multadas e tenham que pagar as custas processuais. Mattos (2017) comprovou que o "planejamento tributário" compensa "principalmente quando se tratam de grandes empresas com gestores especializados e oportunidades diversificadas de planejamento tributário" (p. 98). Na prática, diferentemente de médias e pequenas empresas, as empresas de grande porte, em geral, não sonegam para suprir déficit de caixa, mas para obter vantagens no mercado financeiro. Destaca-se que a maioria das grandes empresas estão enquadradas no regime tributário do Lucro Real, regime que facilita a evasão porque, enquanto as empresas enquadradas no Simples Nacional e no Lucro Presumido são tributadas pela receita bruta "facilmente" auditável -, no Lucro Real existe uma série de possibilidades de evadir, as quais vão muito além da análise da receita bruta.

Rezende (2015) revelou que 394 empresas brasileiras listadas na bolsa de valores enquadradas no Lucro Real - registraram passivos de contingentes tributários na ordem de 837 bilhões de reais apenas no ano de 2013, ou seja, aproximadamente a metade do total arrecadado no país, e, que os incentivos fiscais geram valor, margem e caixa às empresas.

Segundo pesquisa realizada pela Tax Justice Network, divulgada pela BBC Brasil em Londres, só no ano de 2010 a sonegação alcançou 490 bilhões de reais.

Nessa mesma linha, aparecem as remissões tributárias. Por exemplo, no ano de 2017, foram criados três programas especiais de regularização tributária (Pert) para as empresas do Lucro Real e Lucro Presumido (Lei 13.496/17), do Simples Nacional (LC 162/18) e do agronegócio (Lei 13.606/18). Nesses programas estão a concessão do perdão de até $100 \%$ das multas e juros de mora e a diminuição, de $2,5 \%$ para $1,7 \%$, da contribuição do empregador rural pessoa jurídica. Enquanto isso, do outro lado do abismo tributário, os trabalhadores assalariados, por meio da tributação que lhes foi imposta, cada vez mais precisam financiar, não o Estado apenas, mas principalmente quem "formalmente os recolhe". O Unafisco Nacional (2017), estima que os programas supracitados representarão 500 bilhões em renúncias fiscais.

O aparato de meios legais à disposição das empresas e, por consequência, dos empresários, principalmente os de grande porte, não param por aí. Os benefícios tributários, especificamente os institutos legais das isenções, não incidências, bases de cálculo e/ou alíquotas reduzidas, alíquotas zero, créditos presumidos e assim por diante compõem o rol de mecanismos tributários que aprofundam severamente a desigualdade tributária brasileira. O regime tributário que mais absorve os benefícios tributários concedidos pela legislação, sem dúvidas, é o regime do Lucro Real. Tanto o PIS quanto a Cofins são não cumulativos apenas nesse regime, ou seja, a possibilidade de créditos desses tributos se dá estritamente nas empresas do Lucro Real, o qual também se mostra maleável na apuração do IRPJ e da CSLL, possibilidades inexistentes para as empresas do Lucro Presumido e do Simples Nacional. Todos esses incentivos à atividade empreendedora não ocorrem apenas na União. Em total sintonia, nas legislações locais ${ }^{30}$ percebem-se movimentos similares.

(30) No Rio Grande do Sul, por exemplo, o Fundopem representa um custo de 700.000,00 por empregado ao "Estado", que tem a Gerdau como maior beneficiária (Meneghetti, 2017). 
Recentemente o Banco Central do Brasil (Bacen, 2020) divulgou o censo de capitais brasileiros no exterior revelando que $63.464^{31}$ pessoas $(60.497$ pessoas físicas e 5.041 pessoas jurídicas) possuem cerca de meio trilhão de dólares aplicados no exterior, ou seja, em abril de 2021, aproximadamente, 2,7 trilhões de reais. Por meio do Regime Especial de Regularização Cambial e Tributária, instituído em 2016, pôde-se perceber que estes recursos estão alocados majoritariamente $(60,4 \%)$ em participações societárias empresariais - inclusive em Offshores - seguidas por fundos de investimentos e outros investimentos em carteira (12,3\%). O local preferido para tais "investimentos" foram as Ilhas Virgens Britânicas, um dos mais importantes paraísos fiscais do mundo.

\section{Rendimentos e tributação: a elite empresarial versus os PME}

No ano-calendário de 2016, os empresários, cujo rendimento mensal foi superior a 320 SM, beneficiaram-se com 122 mil de deduções médias da base de cálculo do imposto sobre a renda, enquanto os empresários enquadrados na faixa de 15 a $20 \mathrm{SM}$, foram beneficiados com apenas 10,7 mil de deduções sobre a base de cálculo do imposto, o mesmo que $91,23 \%$ a menos que seus pares mais ricos (Brasil, 2019).

O topo da renda empresarial é beneficiado pelo Estado com 70,22\% de rendimentos isentos (6,69\% dos rendimentos tributados e $23,09 \%$ tributados exclusivamente na fonte) enquanto os empresários, cujo rendimento vai de 15 a 20 SM, encontram uma estrutura tributária menos favorecida de seus pares. Em média, possuem 59,98\% de seus rendimentos isentos, 34,30\% de rendimentos tributados e 5,72\% dos rendimentos tributados exclusivamente na fonte. Notadamente, o topo da renda empresarial possui maior isenção e maior tributação exclusiva na fonte, cujas alíquotas - em parte - são neutras (Brasil, 2019).

Destarte, acrescentam-se as descobertas de Mills (1969), ao descrever sobre os pequenos empresários e profissionais liberais (norte-americanos), e por Pernías (2017), ao dissertar sobre esses profissionais na estrutura social brasileira contemporânea, quando tecem diversas considerações elucidando a deletéria condição tributária à que estão expostos os trabalhadores assalariados e os PME.

\section{Tributação sobre a renda do capital: empresários versus trabalhadores assalariados}

No mesmo lado da moeda, se a tributação sobre a renda e o consumo é bem mais pesada aos trabalhadores assalariados, a escassa tributação brasileira sobre o patrimônio, ou sobre a renda desse, também os penaliza. Os empresários, por meio de suas holdings, recolhem (des)proporcionalmente bem menos tributos, como pode ser observado na tabela a seguir.

Tabela 2

Diferenças na tributação sobre a renda do capital

\begin{tabular}{c|c|c|c}
\hline & $\begin{array}{c}\text { Patrimônio do } \\
\text { trabalhador assalariado }\end{array}$ & $\begin{array}{c}\text { Patrimônio integralizado } \\
\text { no estoque de imóveis }- \\
\text { Holding patrimonial }\end{array}$ & $\begin{array}{c}\% \text { máximo da vantagem } \\
\text { tributária }\end{array}$ \\
\hline Tributação na venda (\%) & De 15\% a 22,5\% & Máximo de $6,73 \%$ & 16,57 \\
\hline Tributação da renda (aluguéis) (\%) & Até 27,5\% & Máximo de $14,53 \%$ & 16,17 \\
\hline
\end{tabular}

Fonte: Elaboração própria.

(31) Números que vêm crescendo conforme a série histórica divulgada pelo Bacen. Disponível em: https://www.bcb.gov.br/publicacoes/relatorioid. Acesso em: 24 abr. 2021. 
Trata-se de mais uma distinção que o STB promoveu aos empresários. Na hipótese de o trabalhador ter um imóvel disponível para locação a terceiros, poderá ter um custo tributário de $142,72 \%$ a mais do que o empresário. Ao vender um imóvel, sem se enquadrar nas situações de isenção, o custo tributário em relação ao empresário, que pode recair ao trabalhador, é de aproximadamente $279,43 \%$ a mais do que o do empresário. Deve-se observar que tamanhas discrepâncias ocorrem horizontal e independentemente de a renda do salário ser esta ou aquela, bastando ter natureza salarial, ou seja, força de trabalho.

\section{Considerações finais}

Descritos alguns dados acerca das principais desigualdades socioeconômicas e concentração de renda e capital no Brasil e no mundo, bem como aspectos deletérios (exceto aos megaempresários) da atual estrutura tributária brasileira, este estudo anseia ter contribuído cientificamente com o debate (histórico) acerca da formatação tributária instigando novos questionamentos.

Ao decorrer da pesquisa surgiram algumas limitações, dentre as quais se destacou a falta de dados sobre o percentual médio referente ao gasto e à respectiva tributação da base de incidência tributária do Consumo nas faixas do topo de renda e capital. Ou seja, atualmente existe uma série de pesquisas que detalham por faixa de Renda e Capital as alíquotas médias da tributação que recai sobre as mesmas, o que possibilitou a comprovação de que o ônus tributário, no Brasil, é proporcionalmente mais elevado às pessoas de baixa renda que, predominantemente, vivem da renda oriunda trabalho. Entretanto, a maior faixa de renda em que se possui dados referente aos gastos e tributação incidente sobre o consumo, até a data de finalização desse estudo, é de quem recebe até 30 salários-mínimos, muito aquém da renda dos $0,1 \%$ e $1 \%$ mais afortunados, de acordo com o que foi descrito.

Ainda que determinados estudos apontem que o gasto em consumo é exponencial e proporcionalmente menor aos mais ricos (o que parece razoável e dedutível), não se tem, por exemplo, qual é o percentual da alíquota média em que esses são tributados na base de incidência tributária do Consumo. Caso existissem esses dados, haveria a possibilidade de estimativa da tributação total (sobre o Consumo, Renda e Capital), em percentuais, que recai (também) sobre os super-ricos, tornando possível a comparação completa entre os mais diferentes estratos de renda. Destarte, acredita-se e estimula-se a necessidade de pesquisas futuras.

Feitos tais apontamentos, relata-se que o presente estudo verificou uma série de mecanismos legais e extralegais, presentes no STB, disponíveis à elite empresarial brasileira e estrangeira, que tendem a penalizar as camadas inferiores e, em análise mais orientada, tendem a contribuir até mesmo para o baixo crescimento econômico.

Além disso, tal estrutura tributária, conforme demonstrado por diversos estudos supracitados, é voltada a perpetuar e aprofundar as desigualdades socioeconômicas, premissas que levam à constatação de que urge o debate democrático acerca da reestruturação tributária para além da recomendada simplificação do STB.

No entanto, ainda que tal debate passe a ser mais democratizado, a presente pesquisa trouxe indícios de que há limites da tributação capitalista. Isso, porque no âmago do sistema capitalista, o lucro aparece como uma lei que não se abala diante de súplicas e rogos e, dessa maneira, a tributação 
não pode pôr em risco o sistema, mas sim, ao contrário: ela necessita ser uma tributação funcional ao capitalismo.

\section{Referências bibliográficas}

BANCO CENTRAL DO BRASIL. CBE - Capitais Brasileiros no Exterior. Disponível em: https://www.bcb.gov.br/publicacoes/relatorioid. Acesso em: 24 abr. 2021.

BRASIL. Decreto-Lei, de 26 de dezembro de 1977. Altera a legislação do imposto sobre a renda. Disponível em: http://www.planalto.gov.br/ccivil_03/decreto-lei/Del1598.htm. Acesso em: 28 maio 2018.

BRASIL. Lei $n$. 13.606, de 09 de janeiro de 2018. Institui o Programa de Regularização Tributária Rural (PRR) na Secretaria da Receita Federal do Brasil e na Procuradoria-Geral da Fazenda Nacional; altera as Leis n. 8.212, de 24 de julho de 1991, 8.870, de 15 de abril de 1994, 9.528, de 10 de dezembro de 1997, 13.340, de 28 de setembro de 2016, 10.522, de 19 de julho de 2002, 9.456, de 25 de abril de 1997, 13.001, de 20 de junho de 2014, 8.427, de 27 de maio de 1992, e 11.076, de 30 de dezembro de 2004, e o Decreto-Lei n. 2.848, de 7 de dezembro de 1940 (Código Penal); e dá outras providências. Disponível em: http://www.planalto.gov.br/ccivil_03/_ato2015-2018/2018/lei/L13606.htm. Acesso em: 17 jun. 2018.

BRASIL. Lei n. 13.496, de 24 de outubro de 2017. Institui o Programa Especial de Regularização Tributária (Pert) na Secretaria da Receita Federal do Brasil e na Procuradoria-Geral da Fazenda Nacional; e altera a Lei n. 12.249, de 11 de junho de 2010, e o Decreto n. 70.235, de 6 de março de 1972. Disponível em: http://www.planalto.gov.br/ccivil_03/_ato2015-2018/2017/Lei/L13496.htm. Acesso em: 17 jun. 2018.

BRASIL. Lei Complementar n. 162, de 06 de abril de 2018. Institui o Programa Especial de Regularização Tributária das Microempresas e Empresas de Pequeno Porte optantes pelo Simples Nacional (Pert-SN). Disponível em: http://www.planalto.gov.br/ccivil_03/leis/lcp/Lcp162.htm. Acesso em: 17 jun. 2018.

BRASIL. Medida Provisória n. 795, de 17 de agosto de 2017. Dispõe sobre o tratamento tributário das atividades de exploração e de desenvolvimento de campo de petróleo ou de gás natural, altera a Lei n. 9.481, de 13 de agosto de 1997, e a Lei n. 12.973, de 13 de maio de 2014, e institui regime tributário especial para as atividades de exploração, desenvolvimento e produção de petróleo, de gás natural e de outros hidrocarbonetos fluidos. Disponível em: http://www.planalto.gov.br/ccivil 03/ ato2015-2018/2017/Mpv/mpv795.htm. Acesso em: 15 ago. 2018.

BRASIL. Ministério da Fazenda. Receita Federal. Centro de Estudos Tributários e Aduaneiros CETA. Dados setoriais 2009/2013. 2015. Disponível em: http://idg.receita.fazenda.gov.br/dados/receitadata/estudos-e-tributarios-e-aduaneiros/estudos-eestatisticas/estudos-diversos/dados-setoriais-2009-2013.pdf. Acesso em: 20 mar. 2018.

BRASIL. Ministério da Fazenda. Receita Federal. Centro de Estudos Tributários e Aduaneiros CETA. Dados setoriais 2016/2018. 2020. Disponível em: 
https://receita.economia.gov.br/dados/receitadata/estudos-e-tributarios-e-aduaneiros/estudos-eestatisticas/estudos-diversos/inform_tribut_sociais_setoriais_pjs-2016-a-2018.pdf. Acesso em: 24 abr. 2021.

BRASIL. Secretaria da Receita Federal. Grandes Números da DIRPF (2007-2013). Brasília: RFB, 2019. Disponível em: http://receita.economia.gov.br/dados/receitadata/estudos-e-tributarios-eaduaneiros/estudos-e-estatisticas/11-08-2014-grandes-numeros-dirpf/grandes-numeros-dirpf-capa. Acesso em: 3 jan. 2020.

BOURDIEU, Pierre. Contrafogos 2: por um movimento social europeu. Zahar, 2001.

CATTANI, Antonio David. Uma sociedade menos desigual é melhor para todos: entrevista concedida a Patrícia Comunello. 3 abr. 2018. Jornal do Comércio, Porto Alegre. Disponível em: http://jcrs.uol.com.br/_conteudo/2018/03/politica/618857-uma-sociedade-menos-desigual-emelhor-para-todos-diz-professor-cattani.html. Acesso em: 31 mar. 2018.

CEPAL. Comisión Económica para América Latina y el Caribe. Panorama Fiscal de América Latina y el Caribe 2015: dilemas y espacios de políticas (LC/L.3961). Santiago de Chile, 2015. Disponível em: https://repositorio.cepal.org/bitstream/handle/11362/37747/1/S1500053_es.pdf. Acesso em: 5 abr. 2018.

DALMOLIN, L.C. A exploração tributária intermediada pelo estado: dos mecanismos tributários anestesiantes à fictio juris. Dissertação (Mestrado em Política Social e Serviço Social)-Universidade Federal do Rio Grande do Sul - UFRGS, Porto Alegre, 2018. Disponível em: https://www.lume.ufrgs.br/handle/10183/187387. Acesso em: 17 fev. 2019.

D'ARAÚJO, P. J. S. A regressividade da matriz tributária brasileira: debatendo a tributação a partir de nossa realidade econômica, política e social. Dissertação (Mestrado em Direito)-Universidade de Brasília - UNB, Brasília, 2015. Disponível em: http://repositorio.unb.br/handle/10482/18748. Acesso em: 29 maio 2018.

FAGNANI, Eduardo et al. Reforma tributária e financiamento da política social: caminhos para o desenvolvimento. Março 2018. (Texto para discussão n. 21 / Reforma Tributária). Disponível em: http://plataformapoliticasocial.com.br/reforma-tributaria-e-financiamento-da-politica-social/.

Acesso em: 4 abr. 2018.

FMI. International Monetary Fund. Fiscal monitor: tackling inequality. Washington, Oct. 2017. Disponível em: http://www.imf.org/ /media/Files/Publications/fiscalmonitor/2017/October/pdf/fm1702.ashx?la=en. Acesso em: 5 abr. 2018.

UNAFISCO Nacional. Diretoria de Defesa Profissional e Assuntos Técnicos Gestão 2016-2019. Parcelamentos Especiais (Refis): prejuízo para o bom contribuinte, a União, os Estados, o Distrito Federal e para os Municípios. (Nota Técnica Unafisco n. 03/2017). Disponível em: http://unafisconacional.org.br/img/publica_pdf/nota_t_cnica_Unafisco_no_03_2017.pdf. Acesso em: 24 abr. 2018.

GOBETTI, S. W.; ORAIR, R. O. Progressividade tributária: a agenda esquecida. Brasília, 2015. Disponível em: http://www.esaf.fazenda.gov.br/backup/premios/premios-1/premios-2015/xx- 
premio-tesouro-nacional-2015-pagina-principal/monografias-premiadas-xx-premio-tesouronacional-2015/tema-3-sergio-gobetti-e-rodrigo-orair. Acesso em: 30 jul. 2017.

GOBETTI, S. W.; ORAIR, R. O. Tributação e desigualdade de renda no Brasil: uma análise a partir da DIRPF. In: LUKIC, Melina Rocha; AFONSO, José Roberto; ORAIR, Rodrigo Octávio; SILVEIRA, Fernando Gaiger (Org.). Tributação e desigualdade. FGV: Casa do Direito, 2017, p. 159-192.

HANNI, Michael; MARTNER, Ricardo. Impacto redistributivo das políticas fiscais na América Latina Revisitado. In: LUKIC, Melina Rocha;_AFONSO, José Roberto; ORAIR, Rodrigo Octávio; SILVEIRA, Fernando Gaiger (Org.). Tributação e desigualdade. FGV: Casa do Direito, 2017, p. 421-449.

INTROÍNI, Paulo Gil Holk; MORETTO, Amilton J. A tributação sobre a renda no Brasil e suas implicações sobre os trabalhadores. InLUKIC, Melina Rocha; AFONSO, José Roberto; ORAIR, Rodrigo Octávio; SILVEIRA, Fernando Gaiger (Org.). Tributação e desigualdade. FGV: Casa do Direito, 2017, p. 339-366.

JIMÉNEZ, Juan Pablo. Desigualdade, Concentração de Renda e Elites Econômicas na América Latina: O Papel da Política Fiscal. In: LUKIC, Melina Rocha; AFONSO, José Roberto; ORAIR, Rodrigo Octávio; SILVEIRA, Fernando Gaiger (Org.). Tributação e desigualdade. FGV: Casa do Direito, 2017, p. 43-81

LETTIERI, Marcelo. Imposto de Renda das Pessoas Físicas no Brasil: A desigualdade escancarada. In: LUKIC, Melina Rocha; AFONSO, José Roberto; ORAIR, Rodrigo Octávio; SILVEIRA, Fernando Gaiger (Org.). Tributação e desigualdade. FGV: Casa do Direito, 2017, p. 107-157.

LIMA, Paulo César. Análise da Medida Provisória n. 795/2017. Brasília: Câmara dos Deputados, out. 2017. (Estudo Técnico). Disponível em: https://www.brasil247.com/attachment/943/Nota\%20Técnica_MP\%20795.pdf?g_dow. Acesso em: 21 jan. 2018.

MATTOS, Alexandre José Negrini de. Maximização da utilidade esperada, planejamento tributário e governança corporativa. 2017. Dissertação (Mestrado em Controladoria e Contabilidade)Faculdade de Economia, Administração e Contabilidade de Ribeirão Preto, Universidade de São Paulo, Ribeirão Preto, 2017. Disponível em: http://www.teses.usp.br/teses/disponiveis/96/96133/tde10082017-144501/. Acesso em: 29 maio 2018.

MEDEIROS, M.; SOUZA, P. H. G. F. Top income shares and inequality in Brazil, 1928-2012. Sociologies in Dialogue, v. 1, n. 1, p. 119-132, 2015. Disponível em: http://www.sbsociologia.com.br/sid/index.php/sid/article/view/2. Acesso em: 18 dez. 2017.

MEDEIROS, M.; SOUZA, P. H. G. F.; CASTRO, F. A. de. O topo da distribuição de renda no Brasil: primeiras estimativas com dados tributários e comparação com pesquisas domiciliares, 20062012. (Top Incomes in Brazil: First Estimates with Tax Data and Comparison with Survey 
Data, 2006-2012). Rio de Janeiro, v. 58, n. 1, jan./mar. 2015. Disponível em: https://papers.ssrn.com/sol3/Papers.cfm?abstract_id=2479685. Acesso em: 29 maio 2018.

MENEGHETTI Neto, A. O desafio das renúncias fiscais gaúchas. 2017. Disponível em: http://cdn.fee.tche.br/eeg/8/4_ALFREDO-MENEGHETTI-NETO.pdf. Acesso em: 21 jan. 2018.

MÉSZÁROS, István. Para além do capital: rumo a uma teoria da transição. Boitempo Editorial, 2015.

MILLS, C. Wright. A nova classe média. Rio de Janeiro: Zahar, 1969. v. 3, p. 380.

MORGAN, Marc. Desigualdade de renda, crescimento e tributação da elite no Brasil: novas evidências reunindo dados de pesquisas domiciliares. In: LUKIC, Melina Rocha; AFONSO, José Roberto; ORAIR, Rodrigo Octávio; SILVEIRA, Fernando Gaiger (Org.). Tributação e desigualdade. FGV: Casa do Direito, 2017, p. 223-259.

MORGAN, Marc. Income concentration in a context of late development: an investigation of top incomes in Brazil using tax records, 1933-2013. Masters. Paris School of Economics, 2015. Disponível em: http://piketty.pse.ens.fr/files/MorganMila2015.pdf. Acesso em: 18 jul. 2017.

MUSGRAVE, R. A.; MUSGRAVE, P. B. Finanças públicas: teoria e prática. Tradução de Carlos Alberto Primo Braga. São Paulo: Editora da Universidade de São Paulo, 1980.

O’CONNOR, James. USA: a crise do Estado capitalista. Rio de Janeiro: Paz e Terra, 1977.

OCDE et al. Estadísticas tributarias en América Latina y el Caribe 2018. Paris: OECD Publishing. Disponível em: https://www.oecd-ilibrary.org/taxation/revenue-statistics-in-latin-america-and-thecaribbean_24104736. Acesso em: 3 abr. 2018.

OCDE. Relatórios econômicos: Brasil, fev. 2018. Disponível em: https://www.oecd.org/eco/surveys/Brazil-2018-OECD-economic-survey-overview-Portuguese.

Acesso em: 22 maio 2018.

OCDE. Revenue Statistics in Latin America 2007-2016, Paris, 2017. Disponível em: http://stats.oecd.org/viewhtml.aspx?datasetcode=RSLACT\&lang=en\#. Acesso em: 3 abr. 2018.

OXFAM. A distância que nos une: um retrato das desigualdades brasileiras. Documento Informativo da OXFAM Brasil, set. 2017b. Disponível em: https://www.oxfam.org.br/sites/default/files/arquivos/Relatorio_A_distancia_que_nos_une.pdf. Acesso em: 7 abr. 2018.

OXFAM. Uma economia para os 99\%. Documento Informativo da OXFAM, jan. 2017a. Disponível em: https://www.oxfam.org.br/publicacoes/uma-economia-para-os-99. Acesso em: 4 abr. 2017.

PAES, Nelson Leitão. Imposto de Renda da Pessoa Física - Uma Análise Comparativa do Brasil em Relação à América Latina. In: In: LUKIC, Melina Rocha; AFONSO, José Roberto; ORAIR, Rodrigo Octávio; SILVEIRA, Fernando Gaiger (Org.). Tributação e desigualdade. FGV: Casa do Direito, 2017, p. 83-106. 
PERNÍAS, Tomás Rigoletto et al. A nova classe média e a inserção dos médicos na estrutura social brasileira: 2003-2013. 2017. Disponível em: http://repositorio.unicamp.br/jspui/handle/REPOSIP/322459. Acesso em: 3 mai. 2018.

PIKETTY, T. O capital no século XXI. Trad. Mônica Baumgarten de Bolle. Rio de Janeiro: Intrínseca, 2014.

PIKETTY. Tributação sobre capital e riqueza no século XXI. In: LUKIC, Melina Rocha; AFONSO, José Roberto; ORAIR, Rodrigo Octávio; SILVEIRA, Fernando Gaiger (Org.). Tributação e desigualdade. FGV: Casa do Direito, 2017, p. 745-760.

REZENDE, Amaury José. Avaliação do impacto dos incentivos fiscais sobre os retornos e as políticas de investimento e financiamento das empresas. Tese (Livre-Docência)-Universidade de São Paulo, 2015.

RODRIGUES, Jefferson José et al. Carga tributária sobre os salários. Brasília: Ministério da Fazenda. Secretaria da Receita Federal. Coordenação-geral de Estudos EconômicoTributários, out. 1998. (Texto para Discussão, n. 01). Disponível em: http://idg.receita.fazenda.gov.br/dados/receitadata/estudos-e-tributarios-e-aduaneiros/estudos-eestatisticas/estudos-diversos/carga-tributaria-sobre-os-salarios. Acesso em: 20 mar. 2018.

SABBAG, Eduardo. Manual de direito tributário. Saraiva Educação SA, 2020.

SALVADOR, E. O injusto sistema tributário brasileiro. Revista Politika, n. 3, mar. 2016. Disponível em: http://www.fjmangabeira.org.br/revistapolitika\#. Acesso em: 18 abr. 2017.

SALVADOR, E. As implicações do sistema tributário brasileiro nas desigualdades e renda. Brasília: Instituto de Estudos Socioeconômicos - INESC, 2014. Disponível em: http://www.inesc.org.br/biblioteca/textos/as-implicacoes-do-sistema-tributario-nas-desigualdadesde-renda/publicacao/. Acesso em: 2 mar. 2017.

SIQUEIRA, Rozane Bezerra de et al. O Sistema Tributário Brasileiro é regressivo? In: LUKIC, Melina Rocha; AFONSO, José Roberto; ORAIR, Rodrigo Octávio; SILVEIRA, Fernando Gaiger (Org.). Tributação e desigualdade. FGV: Casa do Direito, 2017, p. 501-528.

TAX FOUNDATION. Corporate income taxes. Disponível em: https://taxfoundation.org/. Acesso em: 27 maio 2018.

UNAFISCO NACIONAL. Refis: 'renúncia fiscal projetada supera 500 bilhões em 15 anos'. 2017. Disponível em: https://unafisconacional.org.br/refis-renuncia-fiscal-projetada-supera-500-bilhoesem-15-anos-disse-a-veja-kleber-cabral/. Acesso em: 26 abr. 2021.

WORLD Top Incomes Database (WTID). Disponível em: http://wid.world/share/\#0/countriestimeseries/sptinc_p99p100_z/US;FR;DE;CN;ZA;GB;WO;XL/la st/eu/k/p/yearly/s/false/4.534/40/curve/false. Acesso em: 3 abr. 2018. 